\title{
A multi-trait meta-analysis with imputed sequence variants reveals twelve QTL for mammary gland morphology in Fleckvieh cattle
}

\author{
Hubert Pausch ${ }^{1 *}$, Reiner Emmerling ${ }^{2}$, Hermann Schwarzenbacher ${ }^{3}$ and Ruedi Fries ${ }^{1}$
}

\begin{abstract}
Background: The availability of whole-genome sequence data from key ancestors in bovine populations provides an exhaustive catalogue of polymorphic sites that segregate within and across cattle breeds. Sequence variants identified from the sequenced genome of key ancestors can be imputed into animals that have been genotyped using medium- and high-density genotyping arrays. Association analysis with imputed sequences, particularly when applied to multiple traits simultaneously, is a very powerful approach to detect candidate causal variants that underlie complex phenotypes.

Results: We used whole-genome sequence data from 157 key ancestors of the German Fleckvieh cattle population to impute 20,561,798 sequence variants into 10,363 animals that had (partly imputed) genotypes based on 634,109 single nucleotide polymorphisms (SNPs). Rare variants were more frequent among the sequence-derived than the array-derived genotypes. Association studies with imputed sequence variants were performed using seven correlated udder conformation traits as response variables. The calculation of an approximate multi-trait test statistic enabled us to detect 12 quantitative trait loci (QTL) $\left(P<2.97 \times 10^{-9}\right.$ ) that affect different morphological features of the mammary gland. Among the tested variants, the most significant associations were found for imputed sequence variants at 11 QTL, whereas the top association signal was observed for an array-derived variant at a QTL on bovine chromosome 14. Seven QTL were associated with multiple phenotypes. Most QTL were located in non-coding regions of the genome but in close proximity of candidate genes that could be involved in mammary gland morphology (SP5, GC, NPFFR2, CRIM1, RXFP2, TBX5, RBM19 and ADAM12).
\end{abstract}

Conclusions: Using imputed sequence variants in association analyses allows the detection of QTL at maximum resolution. Multi-trait approaches can reveal QTL that are not detected in single-trait association studies. Most QTL for udder conformation traits were located in non-coding regions of the genome, which suggests that mutations in regulatory sequences are the major determinants of variation in mammary gland morphology in cattle.

\section{Background}

Genome-wide association studies (GWAS) using dense single nucleotide polymorphisms (SNPs) have facilitated the identification of quantitative trait loci (QTL) for numerous phenotypes. However, because of the extensive

\footnotetext{
${ }^{*}$ Correspondence: hubert.pausch@tierzucht.tum.de

${ }^{1}$ Lehrstuhl fuer Tierzucht, Technische Universitaet Muenchen,

85354 Freising, Germany

Full list of author information is available at the end of the article
}

linkage disequilibrium (LD) that is present in bovine populations, the QTL regions are often very large, which makes the identification of underlying genes and variants usually inefficient. Moreover, the current genotyping arrays interrogate only a limited number of polymorphic sites that are primarily located in non-coding regions of the genome [1].

The availability of whole-genome sequences has led to an exhaustive catalogue of polymorphic sites that 
segregate within and across bovine populations [2, 3]. However, the costs of sequencing the whole genome for a large number of animals are still high, thus, using a relatively low number of sequenced key ancestors as reference animals to impute sequence variants into any animal for which dense genotyping data are available, is an interesting alternative $[4,5]$. Association studies with imputed sequence variants can then pinpoint candidate causal variants that control complex trait variation $[3,6]$.

Computationally efficient algorithms have been developed to perform association studies on thousands of individuals that are genotyped at millions of polymorphic sites (e.g., $[7,8])$. In cattle, such association studies are generally performed within breeds on a trait-by-trait basis and by testing one variant at a time. Association analyses that include multiple phenotypes may be more powerful to identify QTL for complex traits, particularly in the case of causal variants that affect multiple correlated phenotypes [9]. However, a multivariate test of association for millions of sequence variants and many phenotypes is computationally challenging [9]. An approximate multi-trait test statistic allows to efficiently combine the results of multiple association studies that were performed separately and thereby increases the power to identify trait-associated variants [10].

Udder conformation traits are routinely recorded in bovine populations during the evaluation of first-crop daughters of test bulls. Phenotypes for such traits are an important source of information because mammary gland morphology is highly correlated with mastitis susceptibility and productive life span [11-13]. Although the definitions of udder conformation traits may vary across breeds, phenotypic records generally describe the morphology and placement of teats and the overall shape of the mammary gland. The heritability of such traits is relatively high and ranges from 0.14 to 0.42 and most traits related to mammary gland morphology are correlated with each other $[11,14]$.

In this paper, we present results that are based on the imputation of whole-genome sequence variants into more than 10,000 Fleckvieh animals that were genotyped using dense SNP arrays. We performed association studies with more than 16 million sequence variants using seven highly correlated udder conformation traits as response variables. The multi-trait meta-analysis enabled us to detect 12 QTL that affect different morphological features of the mammary gland in Fleckvieh cattle.

\section{Methods}

Animal ethics statement

DNA of artificial insemination bulls was prepared from semen samples that were collected by approved commercial artificial insemination stations as part of their regular breeding and reproductive measures in cattle industry. No ethical approval was required for this study.

\section{Genotypes of the target population}

All animals were genotyped using medium- and highdensity SNP arrays. The high-density dataset consisted of 3545 Fleckvieh animals that had previously been genotyped with the Illumina BovineHD Bead chip that includes 777,962 SNPs. The medium-density dataset consisted of 7073 Fleckvieh animals that had been genotyped with the Illumina BovineSNP50 Bead chip (version 1 and version 2) comprising approximately 54,000 SNPs. Chromosomal positions of SNPs were based on the UMD3.1 assembly of the bovine genome [15]. Mitochondrial, X-chromosomal, Y-chromosomal SNPs and SNPs that had no known chromosomal position were not considered for further analyses. Quality controls were carried out separately for each dataset as described by Pausch et al. [16] and briefly indicated here: SNPs were retained if they had a call rate per SNP and a call rate per individual greater than $90 \%$ and a minor allele frequency (MAF) higher than $0.5 \%$ and if they showed no deviation from the Hardy-Weinberg equilibrium $(\mathrm{P}>0.0001)$ and no pedigree conflicts. After quality control, the medium-density genotypes were imputed to higher density using a combination of Beagle [17] and Minimac [18] as described by Pausch et al. [5]. Only SNPs with a MAF higher than $0.5 \%$ were retained after imputation. The final array-derived dataset consisted of 10,363 animals with (partly imputed) genotypes at 634,109 autosomal SNPs.

\section{Generation of sequence data}

We used whole-genome sequence data from 263 animals that represented 10 bovine breeds, among which the Fleckvieh breed with 157 animals. Most of the sequenced animals were key ancestors for their breeds [19]. The generation and analysis of whole-genome sequence data are described by Pausch et al. [20]. SNPs, short insertions and deletion polymorphisms were genotyped for all 263 sequenced animals simultaneously using the multisample approach implemented in the mpileup module of SAMtools [21] and in a variant calling pipeline described by Jansen et al. [2]. A total of 25,426,490 polymorphic sites were identified. The functional effects of the sequence variants were analyzed using the annotation of the UMD3.1 assembly of the bovine genome [22] and as described by Jansen et al. [2]

\section{Imputation of sequence variants}

The imputation reference panel consisted of 157 sequenced Fleckvieh animals with 20,561,798 autosomal variants. Haplotypes were inferred using Beagle [17] and served as 
reference to impute genotypes for 20,561,798 variants into 10,363 target animals with (partly imputed) genotypes at 634,109 SNPs (see above) using Minimac [18].

\section{Phenotypes tested for association}

Response variables for the association tests were daughter yield deviations (DYD) with an accuracy greater than 0.7 for seven udder conformation traits (teat thickness, teat length, teat position, udder depth, central ligament, fore udder attachment and fore udder length). Depending on the trait, the number of animals with phenotypes ranged from 5470 to 7159 (Table 1). In addition, association tests with 682,047 imputed sequence variants located on BTA14 (BTA for Bos taurus chromosome) were carried out on 6838 animals using DYD for height at the sacral bone as response variable.

\section{Single-trait genome-wide association studies}

We considered 16,816,809 imputed sequence variants with a MAF higher than $0.5 \%$ for the GWAS. The imputed sequence variants were tested for association with each trait in turn using a two-step variance component-based approach that accounts for population stratification and the resulting inflation of false positive association signals by fitting a genomic relationship matrix. The EMMAX software tool [7] was used to fit the model $\mathbf{y}=\mu+\mathbf{u}+\mathbf{e}$, where $\mathrm{y}$ is a vector of DYD, $\mu$ is the intercept, $\mathbf{u}$ is a vector of additive genetic effects $\sim \mathrm{N}\left(0, \mathbf{G} \sigma_{\mathrm{a}}^{2}\right)$, where $\mathbf{G}$ is the realized genomic relationship matrix that was built based on the genotypes of 634,109 autosomal SNPs for the 10,363 animals following VanRaden's approach [23] and $\sigma_{\mathrm{a}}^{2}$ is the additive genetic variance. $\mathbf{e}$ is a vector of residuals $\sim \mathrm{N}\left(0, \mathbf{I} \sigma_{\mathrm{e}}^{2}\right)$, where $\mathbf{I}$ is the identity matrix and $\sigma_{e}^{2}$ is the error variance. In a second step, the allele substitution effect (b) was obtained from a generalized linear regression model: $\mathbf{y}=\mu+\mathbf{x b}+\boldsymbol{\eta}$, where $\mathbf{x}$ is a vector of expected allele dosages and $\boldsymbol{\eta}$ is a vector of random residual deviates with variance $\mathbf{G} \sigma_{\mathrm{a}}^{2}+\mathbf{I} \mathbf{\sigma}_{\mathrm{e}}^{2}$. Inflation factors were calculated using the estlamdba()-function of GenABEL [24]. Sequence variants with a $P$ value less than $2.97 \times 10^{-9}$ were considered as significantly associated (5 \% Bonferroni-corrected significance threshold for 16,816,809 independent tests). The proportion of DYD variance explained per QTL was estimated by $\frac{2 \mathrm{p}(1-\mathrm{p}) \alpha^{2}}{\sigma^{2}}$, where $\mathrm{p}$ and $\alpha$ are the frequency and substitution effect, respectively, of the minor QTL allele and $\sigma^{2}$ is the DYD variance. An analysis conditional on the most significantly associated variant was carried out by taking the expected allele dosages of the top variant as covariates in the linear regression model (see above).

\section{Multi-trait meta-analysis}

An approximate multi-trait test statistic was calculated for 16,816,809 imputed sequence variants using $\chi_{\mathrm{df}=\mathrm{n}}^{2}=\mathbf{t}_{\mathbf{i}}^{\prime} \mathbf{V}^{-1} \mathbf{t}_{\mathbf{i}}$, where $\mathrm{n}$ is the number of traits, $\mathbf{t}_{\mathbf{i}}$ is a $n \times 1$ vector of $t$ values $\left(t=\frac{b}{\operatorname{se}(b)}\right)$ of the ith SNP and $\mathbf{V}^{-1}$ is the inverse of the $\mathrm{n} \times \mathrm{n}$ correlation matrix of $\mathrm{t}$ values [10]. The correlation matrix $\mathbf{V}$ was constructed from $\mathrm{t}$ values of 16,816,809 imputed sequence variants. Sequence variants with a $\mathrm{P}_{\text {META }}$ value less than $2.97 \times 10^{-9}$ were considered as significantly associated (see above).

\section{Results}

More than 20 million sequence variants were imputed into 10,363 animals that had (partly imputed) arrayderived genotypes for 634,109 SNPs (Fig. 1a). The distributions of the allele frequencies of the imputed sequence (SEQ) variants and of the array-derived variants differed. Variants from medium- (50 K) and high-density (700 K) SNP arrays were almost uniformly distributed across different MAF classes, whereas the imputed sequence variants were enriched for low-frequency MAF classes (Fig. 1b). The proportions of variants with a MAF lower than 0.05 were equal to $10.66,9.04$ and $40.52 \%$ and the average MAF was equal to $0.249,0.260$ and 0.145 for the $50 \mathrm{~K}, 700 \mathrm{~K}$ and SEQ datasets, respectively.

Table 1 Characteristics of seven udder conformation traits

\begin{tabular}{|c|c|c|c|c|c|c|c|}
\hline \multirow[t]{2}{*}{ Phenotype (and abbreviation) } & \multirow{2}{*}{$\begin{array}{l}\text { Number of animals } \\
\text { with phenotypes }\end{array}$} & \multicolumn{3}{|c|}{ Distribution of the DYD } & \multicolumn{3}{|c|}{ Accuracy of the DYD } \\
\hline & & Min & Max & Mean $( \pm s d)$ & Min & Max & Mean ( \pm sd) \\
\hline Udder depth (UD) & 7110 & -2.22 & 2.75 & $0.11( \pm 0.64)$ & 0.71 & 0.99 & $0.91( \pm 0.04)$ \\
\hline Teat thickness (TT) & 7108 & -2.32 & 2.17 & $0.04( \pm 0.52)$ & 0.71 & 0.99 & $0.91( \pm 0.04)$ \\
\hline Teat length (TL) & 7159 & -2.61 & 2.52 & $-0.02( \pm 0.66)$ & 0.71 & 0.99 & $0.93( \pm 0.04)$ \\
\hline Teat placement (TP) & 7108 & -1.92 & 2.50 & $0.16( \pm 0.55)$ & 0.71 & 0.99 & $0.91( \pm 0.04)$ \\
\hline Fore udder length (FUL) & 7034 & -2.03 & 2.15 & $0.21( \pm 0.51)$ & 0.71 & 0.99 & $0.88( \pm 0.04)$ \\
\hline Central ligament (CL) & 6923 & -2.24 & 2.32 & $0.11( \pm 0.57)$ & 0.71 & 0.99 & $0.85( \pm 0.05)$ \\
\hline Fore udder attachment (FUA) & 5470 & -2.73 & 2.48 & $0.13( \pm 0.65)$ & 0.71 & 0.99 & $0.87( \pm 0.05)$ \\
\hline
\end{tabular}



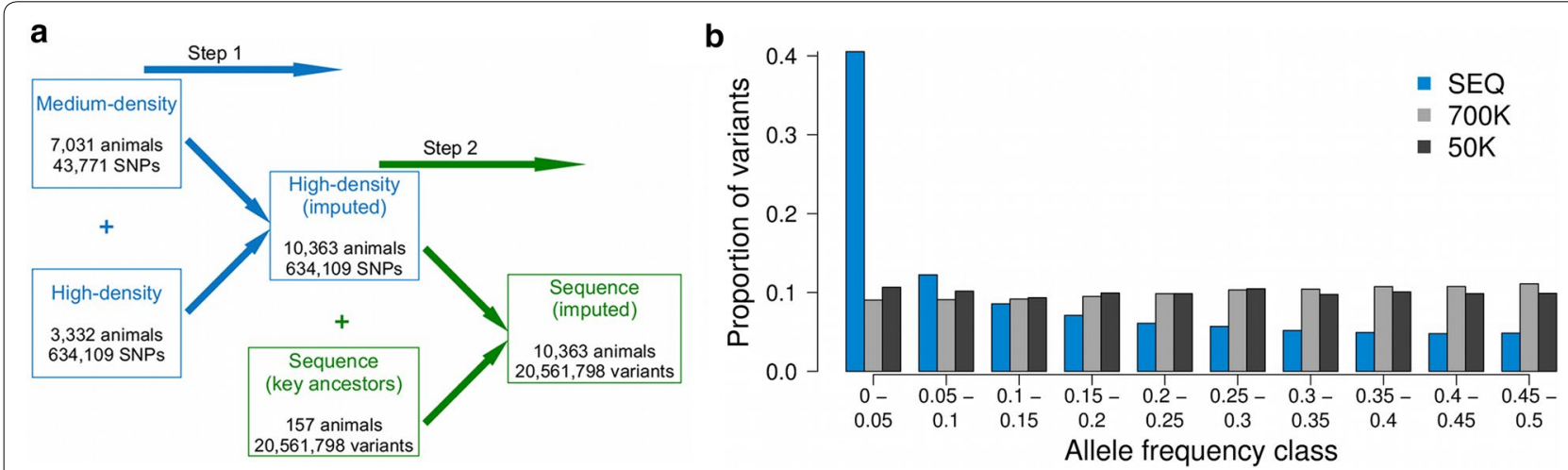

Fig. 1 Imputation of sequence variants. a Overview of the stepwise imputation of 20,561,798 sequence variants into 10,363 Fleckvieh animals. b Distribution of allele frequencies of imputed and array-derived variants. Blue and shades of grey represent the proportion of imputed sequence (SEQ) and array-derived (50 K, $700 \mathrm{~K}$ ) variants, respectively, for ten allele frequency classes

\section{Association studies with udder conformation traits}

We performed association studies between $16,816,809$ imputed sequence variants with a MAF higher than $0.5 \%$ and DYD for seven udder conformation traits (Table 1). The inflation factors of the association studies ranged from 1.04 (central ligament) to 1.08 (udder depth) with an average inflation factor of 1.06 , which indicated that population stratification was under control. The number of QTL detected per trait ranged from zero (fore udder attachment) to five (fore udder length and teat placement) [See Additional file 1: Figure S1]. Correlation coefficients between the seven traits were calculated with the signed $t$ values (i.e., allele substitution effect divided by its standard error, Fig. 2a). The highest correlations were observed between udder depth and fore udder attachment $(r=0.47)$, teat length and teat thickness $(r=0.46)$ and central ligament and teat placement $(r=0.37)$.
A meta-analysis of the seven single-trait association studies revealed 11 QTL $\left(\mathrm{P}_{\text {META }}<2.97 \times 10^{-9}\right)$ located on 11 chromosomes (Fig. 2b; Table 2). The most significantly associated variants were imputed sequence variants at ten QTL and the top association signal was found for an array-derived SNP at the QTL on BTA14. The multi-trait meta-analysis revealed a QTL on BTA2 $\left(\mathrm{P}_{\text {META }}=6.1 \times 10^{-10}\right)$ that was not detected in the single-trait association studies. Closer inspection revealed that the QTL on BTA2 was associated with fore udder attachment $\left(\mathrm{P}_{\text {SINGLE }}=1.13 \times 10^{-6}\right)$, teat thickness $\left(\mathrm{P}_{\text {SINGLE }}=2.68 \times 10^{-4}\right)$, fore udder length $\left(\mathrm{P}_{\text {SINGLE }}=4.37 \times 10^{-3}\right)$ and udder depth $\left(\mathrm{P}_{\text {SIN- }}\right.$ $\left.\mathrm{GLE}=5.01 \times 10^{-3}\right)$, although the $\mathrm{P}_{\text {SINGLE }}$ values were above the Bonferroni-corrected genome-wide significance threshold. Four QTL on BTA14, 21, 27 and 29 that were associated with teat placement, udder depth, teat

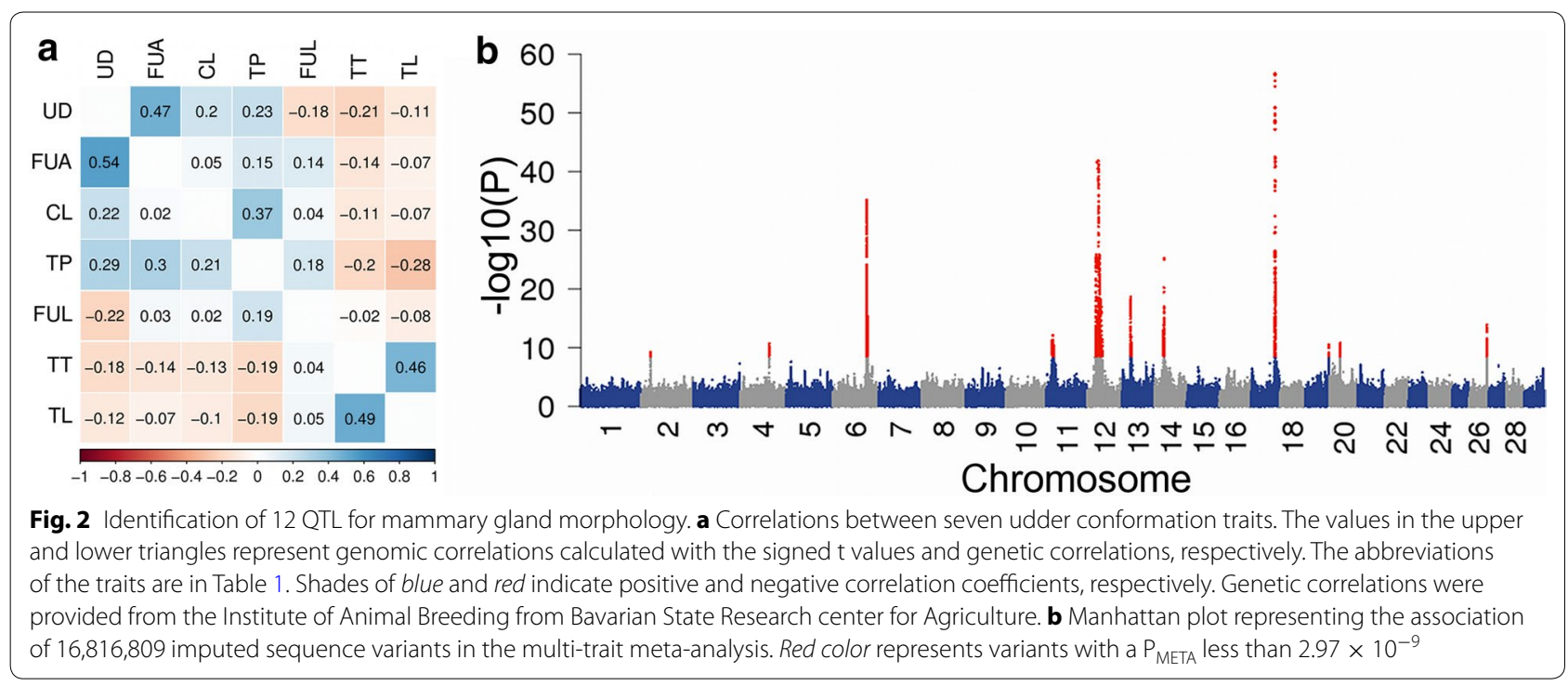


Table 2 Chromosomal positions of 12 QTL for udder morphology detected in the meta-analysis

\begin{tabular}{llllll}
\hline Chr & Position & $\begin{array}{l}\text { NCBI reference } \\
\text { ID }\end{array}$ & MAF & $\mathbf{P}_{\text {META }}$ & $\begin{array}{l}\text { Candidate } \\
\text { gene(s) }\end{array}$ \\
\hline 2 & 25887326 & rs 718110021 & 0.25 & $6.1 \times 10^{-10}$ & SP5 \\
4 & 75817266 & rs474527669 & 0.24 & $1.9 \times 10^{-11}$ & - \\
6 & 88723742 & rs 436532576 & 0.47 & $7.4 \times 10^{-36}$ & GC, NPFFR2 \\
$6^{a}$ & 90366765 & rs516920231 & 0.21 & $8.5 \times 10^{-16}$ & RASSF6 \\
11 & 18757907 & rs384497140 & 0.28 & $7.5 \times 10^{-13}$ & CRIM1 \\
12 & 29248113 & rs381918313 & 0.03 & $1.6 \times 10^{-42}$ & RXFP2 \\
13 & 22699039 & rs109467286 & 0.29 & $2.2 \times 10^{-19}$ & - \\
14 & 25015640 & rs109815800 & 0.12 & $6.2 \times 10^{-26}$ & PLAG1 \\
17 & 62694032 & rs109134926 & 0.25 & $2.2 \times 10^{-57}$ & TBX5, RBM19 \\
19 & 61493292 & rs379185255 & 0.35 & $3.4 \times 10^{-11}$ & - \\
20 & 27355591 & rs378730330 & 0.15 & $1.8 \times 10^{-11}$ & - \\
26 & 46058305 & rs42442597 & 0.34 & $1.3 \times 10^{-14}$ & ADAM12 \\
\hline
\end{tabular}

The positions of the QTL correspond to the UMD3.1 assembly of the bovine genome

Chr chromosome number, MAF minor allele frequency

${ }^{a}$ Marks a QTL that was detected in the conditional analysis

length and udder depth, respectively, were not identified in the multi-trait meta-analysis [See Additional file 1: Figure S1]. Closer inspection of these four regions in the multi-trait meta-analysis showed an association $(7.91 \times 1$ $\left.0^{-8}<\mathrm{P}_{\mathrm{META}}<1.98 \times 10^{-6}\right)$, but not at the genome-wide significance.

To test if a QTL was completely tagged by the top variant, the most significantly associated variant was fitted as a covariate in the single-trait GWAS model and the multi-trait test statistic was re-calculated. The conditional analysis revealed that the associated region on BTA6 consisted of two distinct closely located QTL [See Additional file 2: Figure S2]. The QTL located at $88,723,742$ bp was associated with udder depth, central ligament and fore udder length, whereas the second QTL located at 90,366,765 bp was associated with teat thickness (Table 2 and [See Additional file 2: Figure S2]). No significant associations were detected for any of the other QTL when the association analysis was conditioned on the respective top SNPs.

Seven QTL were associated with multiple morphological features of the mammary gland (Table 2 and Fig. 3). The QTL on BTA17 was associated with four phenotypes. Two and four QTL were associated with three and two udder conformation traits, respectively.

\section{Genes located in the 12 QTL regions detected in the meta-analysis}

To detect positional and functional candidate genes that could be involved in mammary gland morphology, we examined the gene content of 12 QTL regions that were

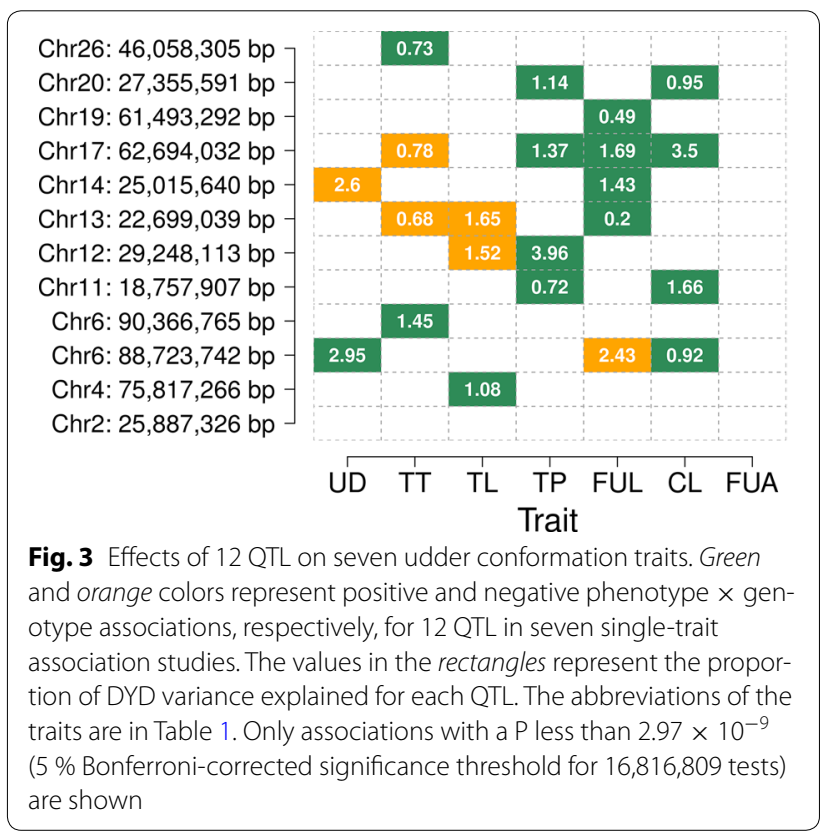

identified in the meta-analysis [See Additional file 3: Figure S3]. However, no annotated genes were present within 300-kb flanking regions of the top association signal on BTA4, 13, 19 and 20, which precluded the identification of positional candidate genes.

Seventy-seven variants with a $\mathrm{P}_{\text {META }}$ value less than $1 \times 10^{-8}$ were located within a $100-\mathrm{kb}$ intergenic segment on BTA2 [See Additional file 3: Figure S3a]. The top association signal $\left(\mathrm{P}_{\mathrm{META}}=6.11 \times 10^{-10}\right)$ was detected for a variant (rs718110021 at 25,887,326 bp) that was located $86 \mathrm{~kb}$ downstream of the stop codon of the $M Y O 3 B$ gene (myosin IIIB) and $111 \mathrm{~kb}$ upstream of the translation start site of the SP5 gene (Sp5 transcription factor).

A QTL region on BTA6 included 1199 variants with a $\mathrm{P}_{\text {META }}$ value less than $1 \times 10^{-14}$ that were located within a 450-kb segment (between 88,613,408 and 89,062,806 bp) [See Additional file 3: Figure S3c]. Two annotated genes reside within this interval: GC (group specific component) and NPFFR2 (neuropeptide FF receptor 2). The top variant $\left(\mathrm{rs} 436532576\right.$ at 88,723,742 bp; $\left.\mathrm{P}_{\text {META }}=7.44 \times 10^{-36}\right)$ was located in the first intron of GC. The most significantly associated coding variant (rs110326785 or NPFFR2: pE389 K; $\mathrm{P}_{\text {META }}=1.86 \times 10^{-16}$ ) was considerably less significantly associated than the non-coding top variant. A second QTL on BTA6 was located $6 \mathrm{~kb}$ downstream of the stop codon of RASSF6 (Ras association (RalGDS/AF-6) domain family member 6) [See Additional file 3: Figure S3d].

Eighty-one variants located within a $1.5-\mathrm{Mb}$ interval on BTA11 (between 18,546,414 and 20,048,201 bp) had $\mathrm{P}_{\text {META }}$ values less than $3.1 \times 10^{-10}$ [See Additional 
file 3: Figure S3e]. This segment encompasses 12 annotated transcripts/genes. The top variant (rs384497140 at $18,757,907 \mathrm{bp} ; \mathrm{P}_{\text {META }}=7.47 \times 10^{-13}$ ) was located $77 \mathrm{~kb}$ upstream of the translation start site of CRIM1 (cysteine rich transmembrane BMP regulator 1 ). Two highly significantly associated coding variants $\left(\mathrm{P}_{\text {META }}<1.58 \times 10^{-10}\right)$ in CRIM1 (rs110451648, p.R540 K) and PRKD3 (rs380476420, p.R861H) were in high LD ( $\left.\mathrm{r}^{2}>0.88\right)$ with the top non-coding variant.

One hundred and twelve variants with a $\mathrm{P}_{\text {META }}$ value less than $1 \times 10^{-30}$ were located in a $4.59-\mathrm{Mb}$ interval (between 25,693,051 and 30,288,956 bp) on BTA12 [See Additional file 3: Figure S3f]. The top association signal $\left(\mathrm{P}_{\text {META }}=1.58 \times 10^{-42}\right)$ was found for an intronic variant (rs381918313 at 29,248,113 bp) in RXFP2 (relaxin/ insulin-like family peptide receptor 2). None of the highly significantly associated variants were located in the coding region of an annotated gene.

The QTL on BTA14 was in a genomic region that controls growth-related traits in cattle $[25,26]$ and other species [27]. The top variant (rs109815800 at 25,015,640 bp, $\mathrm{P}_{\text {META }}=6.23 \times 10^{-26}$ ) was located $6 \mathrm{~kb}$ upstream of the translation start site of PLAG1 (pleiomorphic adenoma gene 1) [See Additional file 3: Figure S3h]. We performed an association analysis with DYD for height at the sacral bone to test if the QTL for mammary gland morphology was also associated with stature. The association analysis revealed that rs109815800 was also the most significantly associated variant for height at the sacral bone $\left(\mathrm{P}=1.07 \times 10^{-52}\right)[$ See Additional file 4: Figure S4]. The allele that increases body height was associated with an increased udder base.

Eighty sequence variants with a $\mathrm{P}_{\text {META }}$ value less than $1.87 \times 10^{-25}$ were located within a $171-\mathrm{kb}$ intergenic segment (between 62,667,848 and 62,838,591 bp) on BTA17 [See Additional file 3: Figure S3i]. The top variant $\left(\mathrm{rs} 109134926\right.$ at $\left.62,694,032 \mathrm{bp} ; \mathrm{P}_{\text {META }}=2.23 \times 10^{-57}\right)$ was located $193 \mathrm{~kb}$ upstream of the translation start site of RBM19 (RNA binding motif protein 19), and $113 \mathrm{~kb}$ downstream of the stop codon of TBX5 (T-box 5 transcription factor).

A QTL on BTA26 was associated with teat thickness. Thirty-nine variants with a $\mathrm{P}_{\text {META }}$ value less than $2.0 \times 10^{-13}$ were located in the third intron of $A D A M 12$ (ADAM metallopeptidase domain 12) [See Additional file 3: Figure S3l]. The top variant (rs42442597 at $\mathrm{P}_{\text {META }}=1.29 \times 10^{-14}$ ) was located at $46,058,305 \mathrm{bp}$. No coding variants were significantly associated with mammary gland morphology.

\section{Discussion}

Sequence variants were extrapolated into 10,363 animals using a two-step genotype imputation approach.
Initially, the animals with medium-density genotypes were imputed to higher density using 3332 reference animals that had been genotyped with a high-density genotyping array. In the second step, the (partly imputed) high-density genotypes were imputed to sequence level using sequence variants of 157 key ancestors of the Fleckvieh population as reference animals. According to Brøndum et al. [28], using a multi-breed reference panel may improve imputation accuracy when the number of reference animals is small. However, the imputation pipeline that we applied was expected to yield high imputation accuracy by using 157 key ancestors as reference animals [5]. Low-frequency variants occurred more often among the imputed than the array-derived variants. This agrees with previous findings in cattle [6] and other species [29]. Since the imputation of rare variants is error prone $[3,5,28]$, we retained only variants with a MAF higher than $0.5 \%$ for the association studies. Moreover, to take imputation uncertainty into account [30], we used the expected allele dosages instead of the most likely genotypes as explanatory variables in the GWAS. Thus, our association analyses should not be flawed due to inaccurately imputed sequence variants.

To eliminate false positive association signals due to population stratification, the genomic relationship based on genome-wide SNP data was considered in the seven separate association studies. The low inflation factors obtained (1.04 to 1.08) show that this corrective measure was successful. Combining the results of the seven separate association studies by calculating an approximate multi-trait test statistic enabled us to reveal 12 QTL for mammary gland morphology. Among these, we detected a QTL on BTA2 that was not found in the single-trait studies, which showed the enhanced capacity of multitrait approaches for detecting QTL, particularly when the phenotypes are correlated $[9,10,31]$. The QTL on BTA2 was associated with four correlated traits, although not on a genome-wide scale. Our finding that QTL, which cannot be detected at a genome-wide significance level in single-trait GWAS, can be uncovered in a multi-trait approach corroborates the findings of O'Reilly et al. [31]. The joint association analysis of multiple phenotypes might be a more powerful approach to detect QTL that underlie correlated traits than the multi-trait test statistic applied in our study [9]. However, phenotypic records were incomplete for some animals in this study, which precluded multivariate association testing without relying on algorithms to estimate missing phenotypes. Four QTL were detected in the single-trait association studies but were not formally identified in the multi-trait metaanalysis. However, the corresponding $\mathrm{P}_{\text {META }}$ values were only slightly above the Bonferroni-corrected genomewide significance threshold. Adjusting for multiple 
testing using Bonferroni-correction assumes that the individual tests are independent from each other. Due to the small effective population size and high LD, this assumption does not hold for genome-wide association studies in livestock populations. The Bonferroni-correction method is prone to over-correction, particularly in association studies that involve millions of sequence variants $[32,33]$, which results in reduced power.

Previously, association studies for udder conformation traits were carried out in several cattle breeds using dense marker maps. Flury et al. [34] identified two QTL for udder length and teat diameter in the Brown Swiss cattle breed on BTA6 located at 88.92 and $90.37 \mathrm{Mb}$, respectively. We also identified two QTL on BTA6 at 88.72 and $90.37 \mathrm{Mb}$, which confirms the crucial role of both regions for mammary gland morphology in cattle. In our study, the QTL on BTA6 were associated with teat thickness and fore udder length, central ligament and udder depth. Hiendleder et al. [35] identified a QTL for udder conformation traits in the Holstein breed on BTA6 at $88 \mathrm{cM}$, which most likely corresponds to the highly significantly associated region(s) identified in our study. Another QTL that affects mammary gland morphology in cattle was reported on BTA17, close to TBX3, TBX5 and $R B M 19$ [34, 36]. The corresponding human chromosome segment is involved in ulnar mammary syndrome [37]. We identified a highly significantly associated QTL at that position with the top variant being only $3 \mathrm{~kb}$ away from the top association signal reported in the Brown Swiss breed [34], which indicates that udder traits may be under the control of a common variant in both breeds. The position of this QTL suggests that regulatory variants may be involved in shaping the mammary gland. An improved functional annotation of the bovine genome [38] and multi-breed association studies with imputed sequence variants may reveal causal mutations for such QTL.

The most significantly associated variants at $11 \mathrm{QTL}$ were imputed sequence variants, which demonstrates that the mapping resolution is increased with wholegenome sequence data relative to array-derived genotypes. However, the top association signal was found for an array-derived variant (rs109815800) at a QTL on BTA14. Interestingly, rs109815800 is one of the eight candidate causative trait variants that were reported for a QTL that affects bovine stature by modulating the expression of PLAG1 [25]. In our study, rs 109815800 was also the top variant for body height, which suggests that it has pleiotropic effects on stature and udder traits. The allele that increased height was also associated with an increased udder base. Udder depth, i.e. the interspace between the ankle and the udder base, is visually examined during the evaluation of first crop daughters of artificial insemination bulls and can be overestimated in tall animals. Thus, the association between PLAG1 and udder depth may reflect phenotypic variation in body size rather than true effects on mammary gland morphology. The fact that this association was not found when udder depth was conditioned on body height further supports this assumption [See Additional file 5: Figure S5].

Our association study revealed new candidate genes for mammary gland morphology in cattle, i.e.:

1. SP5, that is located near a QTL on BTA2: since SP5 is a downstream target gene of the Wnt signaling pathway [39], our result provides additional evidence for the crucial role of the Wnt signaling pathway for mammary gland development in cattle [36];

2. GC and NPFFR2 that are within a QTL on BTA6 and are known to affect mastitis susceptibility in cattle [40-42]; in our study, this QTL was associated with udder depth and central ligament and since udder depth, central ligament and mastitis susceptibility are negatively correlated traits [13], this QTL may contribute to the unfavorable genetic correlation between deep udder base and udder health;

3. CRIM1 that is located close to a QTL on BTA11 and contains an insulin-like growth factor-binding domain [43];

4. RXFP2 near a QTL on BTA12;

5. ADAM12 for which a QTL on BTA26 is located in an intronic region and which encodes the ADAM metallopeptidase domain 12 that interacts with insulin-like growth factor-binding proteins [44]; these findings suggest a crucial role of insulin-like growth factors and insulin-like growth factor-binding proteins during mammary gland development $[45,46]$.

Most of the QTL that we identified in this study reside in non-protein coding regions of the genome, which indicates that mutations in the regulatory regions of genes have a major role in shaping mammary gland morphology in cattle. Pinpointing causal mutations in non-coding elements is notoriously difficult since the annotation of the bovine genome is not always reliable due to assembly errors and the presence of gaps in the reference sequence [22]. Moreover, regulatory elements in the bovine genome are poorly characterized. Thus, we did not attempt to identify candidate causal variants for QTL. However, an improved functional annotation of the bovine genome is expected to facilitate a more precise characterization of regulatory QTL in the future [38].

\section{Conclusions}

Association analyses based on imputed sequence variants allows the characterization of QTL at maximum 
resolution. Variants that affect multiple correlated traits are most efficiently uncovered by their simultaneous analysis using a multi-trait test statistic. Our study revealed 12 QTL that control different features of the mammary gland morphology in the German Fleckvieh cattle population. The positions of the QTL suggest that mutations in the regulatory elements have a major role in shaping mammary gland morphology in cattle.

\section{Additional files}

Additional file 1: Figure S1. Manhattan plots representing the association between 16,816,809 imputed sequence variants and seven udder conformation traits.

Additional file 2: Figure S2. Detailed view of the QTL on BTA6.

Additional file 3: Figure S3. Gene content within 12 QTL regions.

Additonal file 4: Figure S4. A QTL for stature on BTA14.

Additional file 5: Figure S5. Detailed view of a QTL for mammary gland morphology on BTA14.

\section{Authors' contributions}

$\mathrm{HP}$ and RF conceived, designed and performed the experiments. RE and HS contributed pedigree, phenotype and genotype data. HP and RF wrote the manuscript. All authors read and approved the final manuscript.

\section{Author details}

${ }^{1}$ Lehrstuhl fuer Tierzucht, Technische Universitaet Muenchen, 85354 Freising, Germany. ${ }^{2}$ Institut fuer Tierzucht, Bayerische Landesanstalt fuer Landwirtschaft, 85586 Poing, Germany. ${ }^{3}$ ZuchtData EDV Dienstleistungen GmbH, 1200 Vienna, Austria.

\section{Acknowledgements}

The generation of sequence data of Fleckvieh animals was funded by the German Federal Ministry of Education and Research (BMBF) within the AgroClustEr "Synbreed-Synergistic plant and animal breeding" (grant ids 0315527B, 0315528A). We acknowledge the Arbeitsgemeinschaft Süddeutscher Rinderzüchter e.V., the Arbeitsgemeinschaft österreichischer Fleckviehzüchter and ZuchtData EDV Dienstleistungen GmbH for providing genotype data. We thank Qualitas AG (CH-Zug) and the Swiss Cattle Breeder Association for funding the sequencing of original Simmental animals.

\section{Competing interests}

The authors declare that they have no competing interests.

Received: 2 November 2015 Accepted: 26 January 2016

Published online: 16 February 2016

\section{References}

1. Koufariotis L, Chen YPP, Bolormaa S, Hayes BJ. Regulatory and coding genome regions are enriched for trait associated variants in dairy and beef cattle. BMC Genomics. 2014;15:436.

2. Jansen S, Aigner B, Pausch H, Wysocki M, Eck S, Benet-Pagès A, et al. Assessment of the genomic variation in a cattle population by resequencing of key animals at low to medium coverage. BMC Genomics. 2013;14:446.

3. Daetwyler HD, Capitan A, Pausch H, Stothard P, van Binsbergen R, Brøndum RF, et al. Whole-genome sequencing of 234 bulls facilitates mapping of monogenic and complex traits in cattle. Nat Genet. 2014;46:858-65.

4. VanRaden PM, O'Connell JR, Wiggans GR, Weigel KA. Genomic evaluations with many more genotypes. Genet Sel Evol. 2011;43:10.
5. Pausch H, Aigner B, Emmerling R, Edel C, Götz KU, Fries R. Imputation of high-density genotypes in the Fleckvieh cattle population. Genet Sel Evol. 2013;45:3.

6. Qanbari S, Pausch H, Jansen S, Somel M, Strom TM, Fries R, et al. Classic selective sweeps revealed by massive sequencing in cattle. PLoS Genet. 2014;10:e1004148.

7. Kang HM, Sul JH, Service SK, Zaitlen NA, Kong SY, Freimer NB, et al. Variance component model to account for sample structure in genomewide association studies. Nat Genet. 2010;42:348-54.

8. Loh PR, Tucker G, Bulik-Sullivan BK, Vilhjálmsson BJ, Finucane HK, Salem $\mathrm{RM}$, et al. Efficient Bayesian mixed-model analysis increases association power in large cohorts. Nat Genet. 2015;47:284-90.

9. Zhou $X$, Stephens M. Efficient multivariate linear mixed model algorithms for genome-wide association studies. Nat Methods. 2014;11:407-9.

10. Bolormaa S, Pryce JE, Reverter A, Zhang Y, Barendse W, Kemper K, et al. A multi-trait, meta-analysis for detecting pleiotropic polymorphisms for stature, fatness and reproduction in beef cattle. PLOS Genet. 2014;10:e1004198.

11. Berry DP, Buckley F, Dillon P, Evans RD, Veerkamp RF. Genetic relationships among linear type traits, milk yield, body weight, fertility and somatic cell count in primiparous dairy cows. Irish J Agric Food Res. 2004;43:161-76.

12. Vollema AR, Groen AF. Genetic correlations between longevity and conformation traits in an upgrading dairy cattle population. J Dairy Sci. 1997:80:3006-14.

13. Pritchard T, Coffey M, Mrode R, Moore K, Wall E. Genetic parameters of udder health traits in Holstein Friesian UK dairy cattle. In: Proceedings of the 9th World Congress on Genetics applied to Livestock Production; 2010, p. 1-8.

14. Kramer M, Erbe M, Bapst B, Bieber A, Simianer H. Estimation of genetic parameters for novel functional traits in Brown Swiss cattle. J Dairy Sci. 2013;96:5954-64.

15. Zimin AV, Delcher AL, Florea L, Kelley DR, Schatz MC, Puiu D, et al. A whole-genome assembly of the domestic cow. Bos taurus. Genome Biol. 2009;10:R42.

16. Pausch $H$, Kölle $S$, Wurmser $C$, Schwarzenbacher $H$, Emmerling $R$, Jansen $\mathrm{S}$, et al. A nonsense mutation in TMEM95 encoding a nondescript transmembrane protein causes idiopathic male subfertility in cattle. PLoS Genet. 2014;10:e1004044.

17. Browning BL, Browning SR. A unified approach to genotype imputation and haplotype-phase inference for large data sets of trios and unrelated individuals. Am J Hum Genet. 2009;84:210-23.

18. Howie B, Fuchsberger C, Stephens M, Marchini J, Abecasis GR. Fast and accurate genotype imputation in genome-wide association studies through pre-phasing. Nat Genet. 2012;44:955-9.

19. Goddard ME, Hayes BJ. Genomic selection based on dense genotypes inferred from sparse genotypes. Proc Assoc Advmt Anim Breed Genet. 2009;18:26-9

20. Pausch H, Schwarzenbacher $\mathrm{H}$, Burgstaller J, Flisikowski K, Wurmser C, Jansen $\mathrm{S}$, et al. Homozygous haplotype deficiency reveals deleterious mutations compromising reproductive and rearing success in cattle. BMC Genomics. 2015;16:312

21. Li H, Handsaker B, Wysoker A, Fennell T, Ruan J, Homer N, et al. The sequence alignment/map format and SAMtools. Bioinformatics. 2009;25:2078-9.

22. Florea L, Souvorov A, Kalbfleisch TS, Salzberg SL. Genome assembly has a major impact on gene content: a comparison of annotation in two Bos taurus assemblies. PLoS One. 2011;6:e21400.

23. VanRaden PM. Efficient methods to compute genomic predictions. J Dairy Sci. 2008;91:4414-23.

24. Aulchenko YS, Ripke S, Isaacs A, van Duijn CM. GenABEL: an R library for genome-wide association analysis. Bioinformatics. 2007;23:1294-6.

25. Karim L, Takeda H, Lin L, Druet T, Arias JAC, Baurain D, et al. Variants modulating the expression of a chromosome domain encompassing PLAG1 influence bovine stature. Nat Genet. 2011:43:405-13.

26. Pausch H, Flisikowski K, Jung S, Emmerling R, Edel C, Götz KU, et al. Genome-wide association study identifies two major loci affecting calving ease and growth-related traits in cattle. Genetics. 2011;187:289-97.

27. Lango Allen H, Estrada K, Lettre G, Berndt SI, Weedon MN, Rivadeneira $\mathrm{F}$, et al. Hundreds of variants clustered in genomic loci and biological pathways affect human height. Nature. 2010;467:832-8. 
28. Brøndum RF, Guldbrandtsen B, Sahana G, Lund MS, Su G. Strategies for imputation to whole genome sequence using a single or multi-breed reference population in cattle. BMC Genomics. 2014;15:728.

29. Lachance J, Tishkoff SA. SNP ascertainment bias in population genetic analyses: why it is important, and how to correct it. BioEssays. 2013;35:780-6.

30. Zheng J, Li Y, Abecasis GR, Scheet P. A comparison of approaches to account for uncertainty in analysis of imputed genotypes. Genet Epidemiol. 2011;35:102-10.

31. O'Reilly PF, Hoggart CJ, Pomyen Y, Calboli FCF, Elliott P, Jarvelin MR, et al. MultiPhen: joint model of multiple phenotypes can increase discovery in GWAS. PLoS One. 2012;7:e34861.

32. Gao X, Becker LC, Becker DM, Starmer JD, Province MA. Avoiding the high Bonferroni penalty in genome-wide association studies. Genet Epidemiol. 2010;34:100-5.

33. Sham PC, Purcell SM. Statistical power and significance testing in largescale genetic studies. Nat Rev Genet. 2014;15:335-46.

34. Flury C, Boschung C, Denzler M, Bapst B, Schnyder U, Gredler B, et al. Genome-wide association study for 13 udder traits from linear type classification in cattle. In: Proceedings of the 10th World Congress on Genetics Applied to Livestock Production: p. 17-22.

35. Hiendleder S, Thomsen H, Reinsch N, Bennewitz J, Leyhe-Horn B, Looft C, et al. Mapping of QTL for body conformation and behavior in cattle. J Hered. 2003;94:496-506.

36. Pausch H, Jung S, Edel C, Emmerling R, Krogmeier D, Götz KU, et al. Genome-wide association study uncovers four QTL predisposing to supernumerary teats in cattle. Anim Genet. 2012;43:689-95.

37. Klopocki E, Neumann LM, Tönnies H, Ropers HH, Mundlos S, Ullmann R. Ulnar-mammary syndrome with dysmorphic facies and mental retardation caused by a novel 1.28 Mb deletion encompassing the TBX3 gene. Eur J Hum Genet. 2006;14:1274-9.
38. Andersson L, Archibald AL, Bottema CD, Brauning R, Burgess SC, Burt DW, et al. Coordinated international action to accelerate genome-tophenome with FAANG, the Functional Annotation of Animal Genomes project. Genome Biol. 2015;16:57.

39. Fancy SPJ, Harrington EP, Baranzini SE, Silbereis JC, Shiow LR, Yuen TJ, et al. Parallel states of pathological Wnt signaling in neonatal brain injury and colon cancer. Nat Neurosci. 2014;17:506-12.

40. Sahana G, Guldbrandtsen B, Thomsen B, Holm LE, Panitz F, Brøndum R, et al. Genome-wide association study using high-density single nucleotide polymorphism arrays and whole-genome sequences for clinical mastitis traits in dairy cattle. J Dairy Sci. 2014;97:7258-75.

41. Ma L, Wiggans GR, Wang S, Sonstegard TS, Yang J, Crooker BA, et al. Effect of sample stratification on dairy GWAS results. BMC Genom. 2012;13:536.

42. Wu X, Lund MS, Sahana G, Guldbrandtsen B, Sun D, Zhang Q, et al. Association analysis for udder health based on SNP-panel and sequence data in Danish Holsteins. Genet Sel Evol. 2015;47:50.

43. Kolle G, Georgas K, Holmes GP, Little MH, Yamada T. CRIM1, a novel gene encoding a cysteine-rich repeat protein, is developmentally regulated and implicated in vertebrate CNS development and organogenesis. Mech Dev. 2000;90:181-93.

44. Shi Z, Xu W, Loechel F, Wewer UM, Murphy LJ. ADAM 12, a disintegrin metalloprotease, interacts with insulin-like growth factor-binding protein-3. J Biol Chem. 2000;275:18574-80.

45. Sureshbabu A, Tonner E, Flint DJ. Insulin-like growth factor binding proteins and mammary gland development. Int J Dev Biol. 2011;55:781-9.

46. Allan GJ, Beattie J, Flint DJ. The role of IGFBP-5 in mammary gland development and involution. Domest Anim Endocrinol. 2004;27:257-66.

\section{Submit your next manuscript to BioMed Central and we will help you at every step:}

- We accept pre-submission inquiries

- Our selector tool helps you to find the most relevant journal

- We provide round the clock customer support

- Convenient online submission

- Thorough peer review

- Inclusion in PubMed and all major indexing services

- Maximum visibility for your research

Submit your manuscript at www.biomedcentral.com/submit

\section{(O) Biomed Central}

